(C) CSIRO 2013. The online version of this article is published within an Open Access environment subject to the conditions of the Creative Commons Attribution-NonCommercial-ShareAlike licence http://creativecommons.org/licenses/by-nc-sa/3.0/. The written permission of Cambridge University Press must be obtained for commercial re-use.

\title{
Habitat-specific seed dormancy-release mechanisms in four legume species
}

\author{
Rieks D. van Klinken ${ }^{1 *}$ and Jean-Baptiste Goulier ${ }^{1,2}$ \\ ${ }^{1}$ CSIRO Ecosystem Sciences, EcoSciences Precinct, PO Box 2583, Brisbane, Qld 4001, Australia; \\ ${ }^{2}$ AgroParisTech Paris Institute of Technology for Life, Food and Environmental Sciences, 16 rue Claude Bernard, \\ F-75231 Paris Cedex 05, France
}

(Received 2 February 2013; accepted after revision 22 April 2013; first published online 11 June 2013)

\begin{abstract}
Physical seed dormancy is a common attribute among plants, and a wide range of dormancy-release mechanisms have been described, but their ecological significance is rarely tested through comparative study. This study tests whether dormancy-release responses to wet heat in four legume species with physical dormancy are correlated with habitat: two wetland species (Mimosa pigra and Parkinsonia aculeata, both dispersed primarily by water) and two terrestrial species (Acacia nilotica and Prosopis pallida, both dispersed primarily through vertebrate herbivores). Dormancy release was compared at three moisture levels ( $80 \%$ relative humidity, saturated and submerged) at constant $\left(20-45^{\circ} \mathrm{C}\right)$ and diurnally fluctuating $\left(20 / 40^{\circ} \mathrm{C}\right)$ temperatures for $14 \mathrm{~d}$. Seed viability was tested by germinating at $25^{\circ} \mathrm{C}$. The functional relationship between temperature and dormancy release after $14 \mathrm{~d}$ differed between species: submerged seeds of the two wetland species showed a quadratic response, with low rates of imbibition below $20-25^{\circ} \mathrm{C}$ and complete imbibition at around $40^{\circ} \mathrm{C}$; P. pallida seeds showed a linear positive relationship, whereas there was no temperature response for $A$. nilotica seeds below $45^{\circ} \mathrm{C}$. Surprisingly, dormancy release after $14 \mathrm{~d}$ was relatively insensitive to moisture levels, although rate of dormancy release was generally slower under drier conditions. Dormancy release was not influenced by fluctuating temperatures. Seed viability was largely unaffected by temperature or moisture regime, although it did differ with species and was lower for non-dormant seeds. Our results suggest that a functional dormancy-release response to wet heat provides important fitness benefits for wetland
\end{abstract}

*Correspondence

Email: rieks.vanklinken@csiro.au species, but not for species dispersed through vertebrate herbivores, for which it may be maladaptive.

Keywords: Acacia nilotica, imbibition, invasive plant, Mimosa pigra, Parkinsonia aculeata, physical dormancy, Prosopis pallida

\section{Introduction}

Physical dormancy occurs across at least 15 plant families (Baskin and Baskin, 1998; Baskin et al., 2000). The seed coat confers physical dormancy through tightly packed palisade cells impregnated with waterrepellent substances (Baskin and Baskin, 1998; Jayasuriya et al., 2009). A wide range of dormancyrelease factors for seeds with physical dormancy have been identified or proposed. Examples include high and diurnally fluctuating dry temperatures, short exposure to intense dry heat from fires, temperature fluctuations at cold temperatures, prolonged exposure to wet heat, fluctuating temperatures under wet conditions, and alternate wetting and drying (McKeon and Mott, 1982; Dillon and Forcella, 1985; Auld and O'Connell, 1991; Norman et al., 2002; van Assche et al., 2003; Baskin and Baskin, 2004; van Klinken and Flack, 2005). However, with the exception of simulated fires (Auld and O'Connell, 1991), there have been few attempts to test the ecological significance of these mechanisms by comparing species from contrasting habitats.

Numerous studies have examined the effect of moisture and temperature on seed germination for species with physical dormancy (e.g. Mareno-Casasola et al., 1994; McDonald, 2002). However, factors required for dormancy release and for germination are often confounded (Thompson and Ooi, 2013). For example, a positive correlation under wet conditions between temperature and germination rate could be 
the result of greater dormancy release, better germinating conditions for species that are already non-dormant, or both. Nonetheless, dormancy release is commonly found to be positively correlated with temperature and with moisture availability, and their interaction (Baskin and Baskin, 1998; van Klinken and Flack, 2005; Hu et al., 2009; Jayasuriya et al., 2009). Dormancy release of seeds of one wetland species, Parkinsonia aculeata L., showed a quadratic response to wet heat, with the proportion released increasing strongly above a temperature threshold (van Klinken and Flack, 2005). Dormancy release was thereby minimized when seeds are under dense ground or canopy cover (where competition will be highest), under water (where seeds will rot or seedlings will drown), deeply buried or on the soil surface; and maximized when there is little competition and when temperature and moisture are not limiting (van Klinken et al., 2006, 2008).

Habitat-dependent dormancy-release mechanisms can be expected, as the ultimate fate of seeds depends on their ability to time germination to maximize subsequent recruitment (Allen and Meyer, 1998). For example, exposure to dry heat from fires ('heat shock') is considered to be the principal dormancy-release mechanism for many species in Mediterranean-type ecosystems where seeds are exposed to hot, dry summers (Auld and O'Connell, 1991; Morrison et al., 1998). Within-species variation in dormancy-release mechanisms has also been documented in response to habitat type, with seeds from two populations being sensitive to wet heat and only one to dry heat (Hu et al., 2009). Sensitivity of dormancy-release mechanisms can also differ within species. For example, responses to dry heat varied within two species along an altitudinal gradient in south-east Australia (Ooi et al., 2012) and wet heat responses differed between two $P$. aculeata populations in northern Australia (van Klinken and Flack, 2005). In contrast, a study comparing physical dormancy of multiple species across contrasting environments found no evidence among Trifolium (clover) species of ecotype-dependent dormancy-release mechanisms (Norman et al., 2002).

In this paper we test for habitat-specific dormancyrelease responses to wet heat among four species with physical seed dormancy. We contrast seeds from two wetland ( $P$. aculeata and Mimosa pigra L.) and two terrestrial [Acacia nilotica (L.) Willd. Ex Delile and Prosopis pallida (Willd.) Kunth.] tropical shrub species that are all highly invasive in Australia (Thorpe and Lynch, 2000). All four species are legumes (Family Leguminosae), but $P$. aculeata belongs to a different subfamily (Caesalpinoideae) to the others (Mimosoideae), and A. nilotica belongs to a different tribe (Acacieae) from M. pigra and P. pallida (Mimoseae). A. nilotica is native from Africa to India (Mackey, 1995) and the other three are native to the Neotropics
(Lonsdale, 1995; Hawkins et al., 2007; van Klinken and Campbell, 2009). P. aculeata grows in diverse climates (arid to wet-dry tropics) and habitats (wetlands that are flooded several months of the year, riparian and terrestrial), but is mostly restricted to seasonally flooded habitats in its native range (van Klinken et al., 2009), and does best in periodically flooded habitats in Australia (Smith et al., 2012). M. pigra is primarily a wetland species in the wet-dry tropics (Lonsdale, 1995). Both P. pallida and A. nilotica are largely restricted to terrestrial habitats that are rarely, if ever, inundated. P. pallida is invasive in arid and semi-arid regions around the world (Tewari et al., 1998; van Klinken and Campbell, 2009) whereas A. nilotica is principally invasive in subtropical and semi-arid Australia (Mackey, 1995). Seeds are borne in pods. Water is the most important dispersal agent for M. pigra and $P$. aculeata whereas most P. pallida and A. nilotica pods are consumed by vertebrate herbivores, with seeds being dispersed through the dung (Mackey, 1995; van Klinken and White, 2011).

Seeds with physical dormancy cannot become physically dormant again once the testa is compromised and there is sufficient moisture for imbibition (Baskin and Baskin, 2004; van Klinken et al., 2008), and there is no evidence for physiological dormancy in our species (Dillon and Forcella, 1985; Mackey, 1995; Gardner et al., 2004; van Klinken and Flack, 2005; and see Methods). We therefore tested whether dormancyrelease responses to moisture and temperature differ between our wetland and terrestrial species. Available evidence suggests species differences in dormancy-release mechanisms. As already described, $P$. aculeata has a quadratic response to wet heat but is not sensitive to fluctuating temperatures per se (van Klinken and Flack, 2005; van Klinken et al., 2006). In contrast, the available evidence suggests that $M$. pigra seeds are only sensitive to fluctuating temperatures in moist conditions, with little temperature effect on dormancy release when tested at constant temperatures (Dillon and Forcella, 1985; Lonsdale et al., 1988; Lonsdale, 1993). Studies on the terrestrial species are more equivocal. Temperature and germination rate were positively and linearly correlated under wet conditions between 15 and $40^{\circ} \mathrm{C}$ (seeds were killed at $45^{\circ} \mathrm{C}$ ) for P. pallida (Gardner et al., 2004, but this study confounded dormancy release and germination), and we found no relevant studies for A. nilotica, although Acacia species are commonly sensitive to dry heat (Auld and O'Connell, 1991). Dormancy-release responses to wet heat can also be sensitive to moisture levels (Jayasuriya et al., 2009), but this has not previously been tested for our study species. We expected dormancy release in our study species to be relatively insensitive to moisture, so as to minimize germination when moisture levels may be insufficient for recruitment. 


\section{Materials and methods}

\section{Seed source}

Mature pods of each species were collected from at least five healthy, large-adult trees: P. aculeata at $20^{\circ} 49^{\prime} \mathrm{S}$ $144^{\circ} 12^{\prime} \mathrm{E}$ on 8 July $2011 ; M$. pigra at $12^{\circ} 32^{\prime} \mathrm{S} 131^{\circ} 07^{\prime} \mathrm{E}$ in March 2011; A. nilotica at $22^{\circ} 30^{\prime} \mathrm{S} 141.06^{\circ} \mathrm{E}$ in November 2009; and P. pallida at $20^{\circ} 49^{\prime} \mathrm{S} 144^{\circ} 12^{\prime} \mathrm{E}$ on 28 November 2005. Pods were subsequently kept under ambient laboratory conditions $\left(20-25^{\circ} \mathrm{C}\right)$ until commencement of the experimental work in July 2011. Seeds were removed from pods by hand, taking care not to scratch the seed coat, and only intact, filled seeds were used in experiments.

\section{Germination experiment}

Trials were conducted in a set of seven controlledtemperature cabinets. Dormancy-release responses were compared under humid (seeds on dry filter paper at $80 \pm 10 \%$ relative humidity), saturated (seeds on wet filter paper, but no free water) and wet (seeds submersed in water) conditions at constant $(20,25,30$, 35,40 and $\left.45^{\circ} \mathrm{C}\right)$ and diurnally fluctuating $\left(20 / 40^{\circ} \mathrm{C}\right.$, $12 \mathrm{~h} / 12 \mathrm{~h}$ ) temperatures (only 20,40 and $20 / 40^{\circ} \mathrm{C}$ for the humid treatment). Experiments were conducted under constant $(24 \mathrm{~h})$ light conditions, as light has previously been shown not to affect release from physical dormancy or subsequent germination (Baskin and Baskin, 1998). Temperatures were checked daily with minimum-maximum thermometers to ensure the settings were accurate, and relative humidity in the humid treatment was confirmed using an iButton data logger (DS1921 G-F5; iButtonLink Technology, East Troy, Wisconsin, USA). Each treatment was replicated through time four times (only two for $P$. aculeata), with temperature treatments being randomly assigned to each cabinet on each occasion to avoid any cabinet effect.

Replicates of 25 seeds were randomly drawn from the total seed pool for each species and assigned to a treatment. Each replicate was placed in a separate plastic box $(75 \times 75 \times 25 \mathrm{~mm})$ each of which was filled either with distilled water preheated to the required temperature (submerged treatment), lined with filter paper moistened to saturation (saturated treatment), or lined with dry filter paper (humid treatment), and closed. Submerged and saturated seed replicates were then placed in a larger plastic box $(215 \times 215 \times 105 \mathrm{~mm})$ together with another open box with free water and sealed. Humid replicates were placed in a second large box without free water.

Fully imbibed (non-dormant) seeds in the saturated and submerged treatments were counted and removed daily for $14 \mathrm{~d}$, by which time the rate of seeds still imbibing was expected to be low, based on a previous study (van Klinken and Flack, 2005). Seeds that had not imbibed after $14 \mathrm{~d}$ were therefore considered dormant. Imbibed seeds were easily identified because they had lost colour clarity, were rubbery to the touch and had swelled to at least 1.5 times their original size. Seeds in the humid treatment were treated differently as they did not imbibe under those conditions so it was not possible to tell visually when they were released from dormancy. In a previous study on $P$. aculeata, most seeds that would imbibe when immersed at $20^{\circ} \mathrm{C}$ would do so within $4 \mathrm{~d}$ (van Klinken and Flack, 2005). Dormancy release was therefore determined by submerging seeds for $4 \mathrm{~d}$ at $20^{\circ} \mathrm{C}$ after $14 \mathrm{~d}$ under humid conditions. Imbibed seeds were removed daily.

Viability of all seeds was determined through germination. Dormant seeds were first individually scarified by abrasion. Seeds were placed into Petri dishes lined with paper towel and kept moist with distilled water at $25^{\circ} \mathrm{C}$, which was considered to be within the optimal range for germination (Mackey, 1995; van Klinken and Flack, 2005; van Klinken and Campbell, 2009), for up to $20 \mathrm{~d}$. Germinated seeds (defined as when the radicle was longer than the seed) were counted daily and discarded. No physiological dormancy was expected, and this was the case as all seeds either germinated (were viable) or rotted, as determined through dissection (were unviable).

\section{Statistical analysis}

A two-factor ANOVA was used to test the effect of moisture and temperature on imbibition for each of the $14 \mathrm{~d}$ that seeds were exposed to a treatment. The arcsine square root transformation was required to make the variance independent. As a species by temperature interaction was always present, species were analysed separately. One analysis of variance was done for submerged and saturated seeds to compare all seven temperatures at which they were tested, and another to include all three moisture levels and the temperatures at which they were tested (20, 40 and $20 / 40^{\circ} \mathrm{C}$ ). Polynomials were fitted to the dormancy release response to constant temperature at $14 \mathrm{~d}$ for each species, using the untransformed data.

The effect of moisture and temperature on viability of dormant and non-dormant seeds (after $14 \mathrm{~d})$ was tested in separate ANOVAs after an arcsine square root transformation. Again, the effect of all seven temperatures on saturated and submerged seeds was tested separately to all moisture treatments and three temperatures. Differences between two values were determined using the least significant difference (LSD). 


\section{Results}

\section{Dormancy release}

The four species showed contrasting relationships between dormancy release after $14 \mathrm{~d}$ and moisture (saturated and submerged treatments) and temperature (Fig. 1). P. aculeata was only affected by temperature $\left(F_{3,18}=90.24 ; P<0.001\right)$, as was A. nilotica $\left(F_{3,42}=20.09 ; P<0.001\right)$. M. pigra was affected by temperature $\left(F_{3,42}=162.33 ; P<0.001\right)$, humidity $\left(F_{1,42}=4.67 ; P<0.05\right)$ and their interaction $\left(F_{1,42}=5.46 ; P<0.05\right)$. P. pallida was also affected by temperature $\left(F_{1,44}=64.48 ; P>0.001\right)$ and humidity $\left(F_{1,44}=4.89 ; P<0.05\right)$, but there was no interaction.

The two wetland species showed similar dormancy release responses to temperature after $14 \mathrm{~d}$ (Fig. 1). P. aculeata was fitted with a cubic polynomial $(\mathrm{b} 1=-78.23 \pm 19.02 ; \mathrm{b} 2=30.17 \pm 6.09$; $\mathrm{b} 3=-2.74 \pm 0.58)(\mathrm{Rsq}=93.4 \%)$ whereas $M$. pigra was fitted as a cubic polynomial $(\mathrm{b} 1=-537 \pm 0.16$; $\mathrm{b} 2=0.25 \pm 0.052 ; \mathrm{b} 3=-0.02 \pm 0.005)$ with an interaction with moisture $(b=0.022 \pm 0.01)($ Rsq $=92.2 \%)$. For both species, dormancy release increased rapidly above a threshold temperature (c. 30 and $25^{\circ} \mathrm{C}$, respectively) with all seeds released from dormancy by c. 45 and $40^{\circ} \mathrm{C}$, respectively. That is, P. aculeata seed were released from dormancy at a higher temperature than M. pigra seed. Dormancy release for submerged seeds was only significantly different (higher) from that of saturated seed for M. pigra, and then only at $30^{\circ} \mathrm{C}$ (Fig. 1).

The relationship between temperature and dormancy release was also best described as a cubic polynomial $(\mathrm{b} 1=55.58 \pm 21.76 ; \mathrm{b} 2=-18.30 \pm 9.96$; $\mathrm{b} 3=1.91 \pm 0.66 ; \mathrm{Rsq}=58.7 \%)$ for the terrestrial species, A. nilotica (Fig. 1c). However, dormancy release was only significantly different at $45^{\circ} \mathrm{C}$. In contrast, the relationship was linear for P. pallida seed $(b=0.0931 \pm 0.0116)$, with a slight effect of moisture apparent across all constant temperatures $($ Rsq $=61.47 \%)$ (Fig. 1d). For both species some seeds were still dormant at $45^{\circ} \mathrm{C} \quad(12.8 \pm 4.5 \%$ and $12.5 \pm 4.5 \%$, respectively).

Dormancy release through time could only be compared between saturated and submerged seeds as they were assessed daily (Fig. 2). Imbibition began within a day of immersion for all species. A temperature effect was significant from day 1 for all species (Fig. 2). In contrast, moisture was only
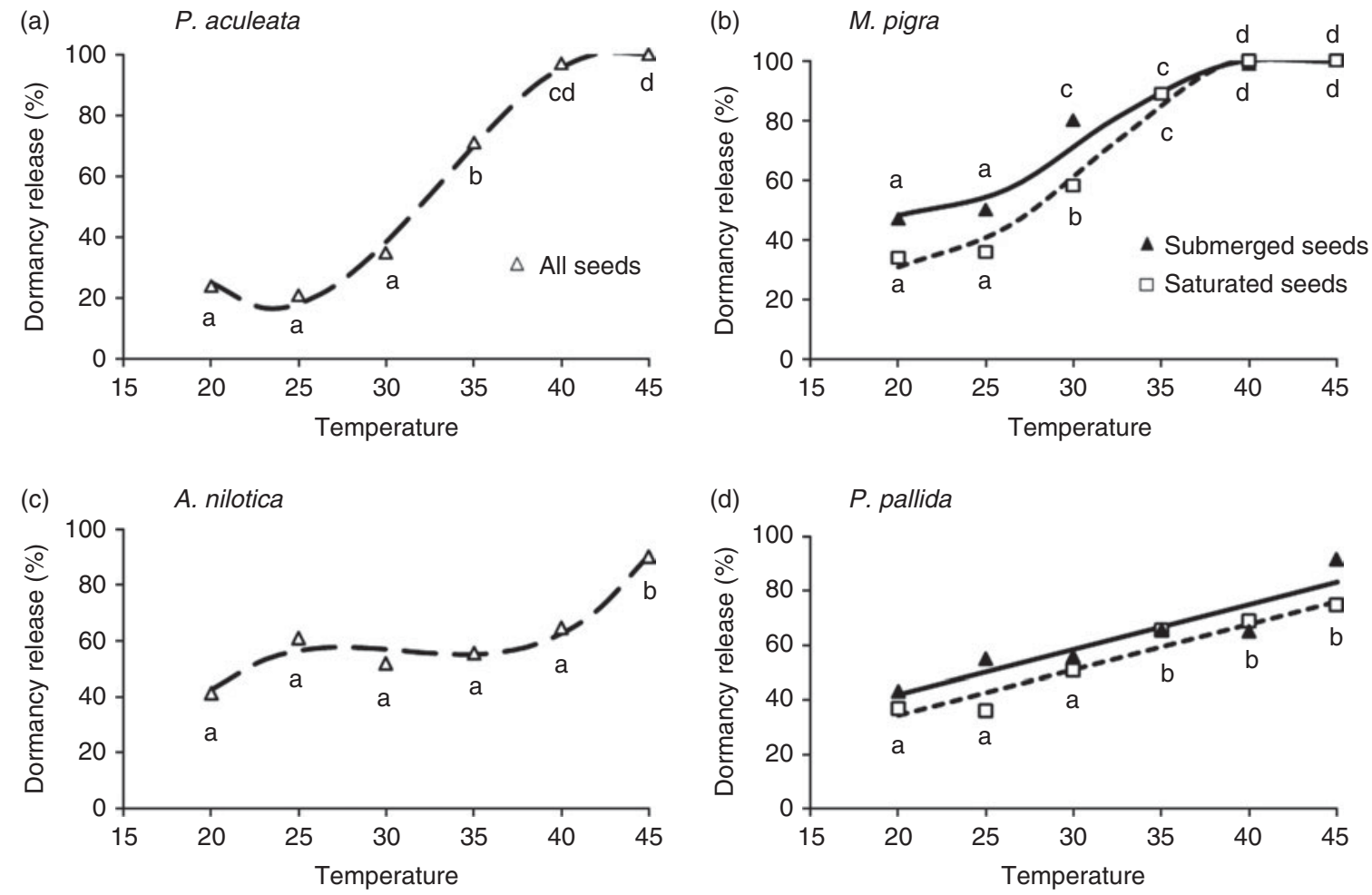

Figure 1. The effect of $14 \mathrm{~d}$ of exposure to constant temperature and moisture (saturated and submerged) conditions on dormancy release for two wetland ( $a$ and b) and two terrestrial ( $c$ and d) species. The relationship between temperature for seeds exposed to saturated or submerged treatments is shown when significant. Moisture treatments are pooled ('all seeds') when there was no moisture effect. Different letters indicate significant difference $(P<0.05)$ between temperatures for the combined moisture treatments, except for $M$. pigra (b) for which there was a significant temperature-moisture interaction (see text). 
(a)

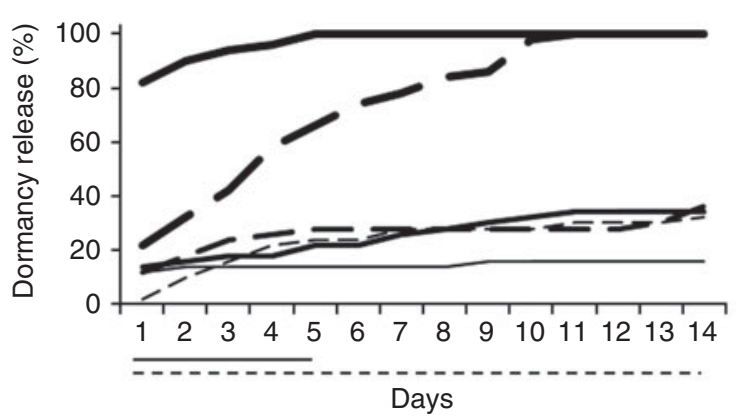

(c)

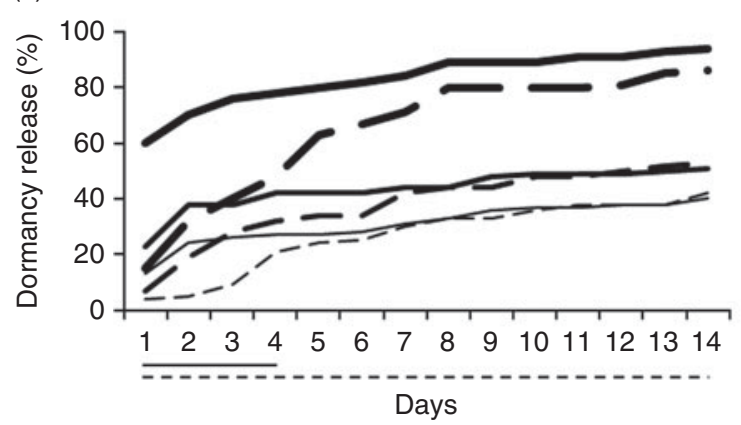

(b) M. pigra

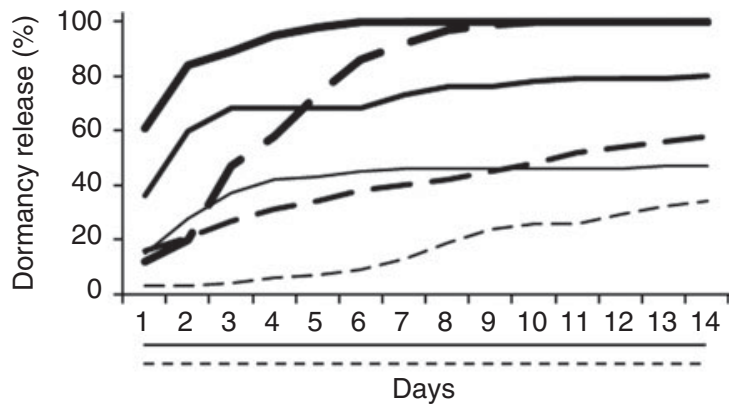

(d) P.pallida

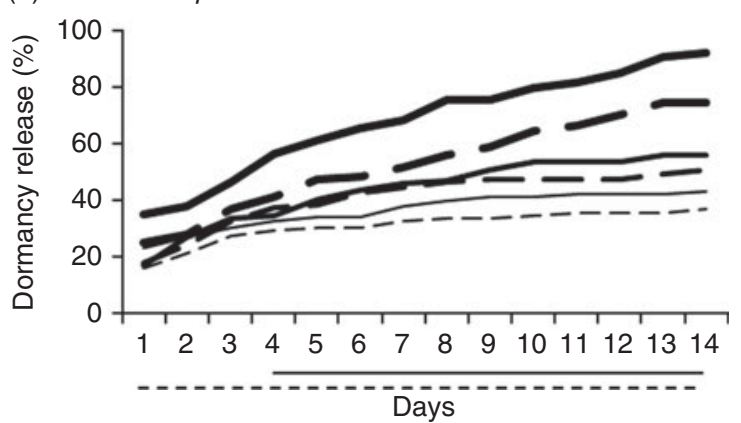

Figure 2. Dormancy release through time for the two wetland (a and b) and two terrestrial (c and d) species for saturated (dashed lines) and submerged seeds (solid lines) illustrated for three temperatures $\left(20,30\right.$ and $45^{\circ} \mathrm{C}$, represented by increasingly thick lines). ANOVAs calculated individually for each day were significant for temperature (dashed lines) and humidity (solid lines) on the days indicated on the $x$ axis.

significant in the first 4 or $5 \mathrm{~d}$ for A. nilotica and P. aculeata, respectively, the last $10 \mathrm{~d}$ for P. pallida, and throughout the 14-d period for $M$. pigra. Rate of dormancy release was much slower under saturated conditions at $45^{\circ} \mathrm{C}$ for the two wetland species and A. nilotica, but was not different from that under submerged conditions for P. pallida.

The dormancy-release analysis comparing the three moisture levels at the three temperatures at which they were all tested $\left(20,40\right.$ and $\left.20 / 40^{\circ} \mathrm{C}\right)$ yielded similar results (Table 1) to the analysis comparing the two moisture levels tested across all temperature treatments (Fig. 1). Again, temperature was significant for $P$. aculeata $\left(F_{2,} 9=30.96 ; P<0.01\right)$ and $A$. nilotica $\left(F_{2,27}=3.97 ; P<0.05\right) ; M$. pigra was affected by temperature $\left(F_{2,27}=139.08 ; P<0.01\right)$, by humidity $\left(F_{2,27}=7.79 ; P<0.01\right)$ and the interaction between these two factors $\left(F_{4,27}=4.50, P<0.01\right)$; and there was an effect of temperature $\left(F_{2,27}=11.72 ; P<0.01\right)$ and humidity $\left(F_{2,27}=3.95 ; P<0.05\right)$ for $P$. pallida. Where there was a significant moisture effect, the humid treatment at constant temperatures was no different to the saturated treatment.

Fluctuating temperature had no effect on dormancy release (Table 1). Dormancy-release under fluctuating temperature conditions $\left(20 / 40^{\circ} \mathrm{C}\right)$ was the same as at $40^{\circ} \mathrm{C}$ or was intermediate (wetland species and P. pallida), or the same as at both 20 and $40^{\circ} \mathrm{C}$ (A. nilotica).

\section{Seed viability}

Most seeds that were still dormant after $14 \mathrm{~d}$ were still viable, although viability did differ with species $\left(F_{3,82}=8.41, P<0.01\right)$ and temperature $\left(F_{2,82}=4.43\right.$, $P<0.05)$. Viability of dormant seeds was highest for wetland species (Table 2), which were also the

Table 1. The effect of temperature and humidity on mean (SE) percentage of seeds released from dormancy (imbibed) after $14 \mathrm{~d}$. Different letters indicate significant differences $(P<0.05)$ within a species

\begin{tabular}{lcccc}
\hline & & \multicolumn{3}{c}{ Dormancy release $(\%)$} \\
\cline { 3 - 5 } Species & $\begin{array}{c}\text { Temperature } \\
\left({ }^{\circ} C\right)\end{array}$ & Humid & Saturated & Submerged \\
\hline P. aculeata & 20 & $60(4)^{\mathrm{a}}$ & $42(6)^{\mathrm{a}}$ & $46(6)^{\mathrm{a}}$ \\
& 40 & $92(8)^{\mathrm{b}}$ & $100(0)^{\mathrm{b}}$ & $100(0)^{\mathrm{b}}$ \\
& $20 / 40$ & $96(0)^{\mathrm{b}}$ & $98(2)^{\mathrm{b}}$ & $98(2)^{\mathrm{b}}$ \\
M. pigra & 20 & $46(8)^{\mathrm{a}}$ & $34(6)^{\mathrm{a}}$ & $47(10)^{\mathrm{a}}$ \\
& 40 & $93(4)^{\mathrm{c}}$ & $100(0)^{\mathrm{c}}$ & $99(2)^{\mathrm{c}}$ \\
& $20 / 40$ & $86(4)^{\mathrm{b}}$ & $87(12)^{\mathrm{b}}$ & $100(0)^{\mathrm{c}}$ \\
A. nilotica & 20 & $50(17)^{\mathrm{a}}$ & $42(9)^{\mathrm{a}}$ & $40(14)^{\mathrm{a}}$ \\
& 40 & $65(3)^{\mathrm{a}}$ & $71(13)^{\mathrm{a}}$ & $58(9)^{\mathrm{a}}$ \\
& $20 / 40$ & $51(14)^{\mathrm{a}}$ & $56(25)^{\mathrm{a}}$ & $58(21)^{\mathrm{a}}$ \\
P. pallida & 20 & $32(6)^{\mathrm{a}}$ & $37(6)^{\mathrm{a}}$ & $37(9)^{\mathrm{a}}$ \\
& 40 & $62(16)^{\mathrm{b}}$ & $69(11)^{\mathrm{b}}$ & $65(15)^{\mathrm{b}}$ \\
& $20 / 40$ & $37(18)^{\mathrm{a}}$ & $60(8)^{\mathrm{b}}$ & $55(18)^{\mathrm{b}}$ \\
\hline
\end{tabular}


youngest seeds (see Methods). For non-dormant seeds, only species had a significant effect $\left(F_{3,102}=68.00\right.$, $P<0.01$ ), with viability being highest for $M$. pigra, intermediate for $P$. aculeata and lowest for the two terrestrial species (Table 2). Overall, viability of nondormant seeds was much lower than for dormant seeds (Table 2). The same factors were significant when just saturated and submerged seeds were compared across all seven tested temperatures, with only species being a significant factor for both dormant $\left(F_{3}, \quad 148=6.45, P<0.01\right)$ and non-dormant $\left(F_{3}\right.$, $185=103.12, P<0.01)$ seeds.

\section{Discussion}

Seeds that only have physical dormancy will either germinate or rot once the hard testa is compromised and there is sufficient moisture for seeds to imbibe water (Baskin and Baskin, 2004). The timing of dormancy release of seeds is therefore particularly critical for restricting opportunities for germination to small windows of time or space when seedling establishment is likely to occur (van Klinken et al., 2008 and references therein). Our study describes diverse dormancy-release responses to two important environmental cues, temperature and moisture. A temperature threshold response to wet heat was evident for two unrelated wetland species but not for two terrestrial species. This supports our hypothesis that species with physical seed dormancy will have habitat-specific dormancy-release mechanisms. Surprisingly, however, the proportion of seeds released from dormancy was relatively insensitive to moisture levels, with similar responses to temperature being observed under high humidity $(80 \% \mathrm{RH})$, saturated conditions and full immersion, although dormancy release rate was slower under drier conditions. Furthermore, fluctuating temperatures $\left(20-40^{\circ} \mathrm{C}\right)$ were not found to be important, despite previous findings to the contrary (Dillon and Forcella, 1985).

Table 2. Mean (SE) viability of seeds (per cent) that were nondormant or dormant after $14 \mathrm{~d}$. There was no moisture effect, but temperature was significant for dormant seeds (see text). Different letters indicate significant differences $(P<0.05)$ among dormant and non-dormant seeds, respectively

\begin{tabular}{lccc}
\hline & \multicolumn{3}{c}{ Seed viability (\%) } \\
\cline { 2 - 4 } Species & $\begin{array}{c}\text { Non-dormant } \\
\text { seeds }\end{array}$ & \multicolumn{2}{c}{ Dormant seeds } \\
\cline { 2 - 4 } \cline { 2 - 4 } P. aculeata & $76.5(4.1)^{\mathrm{b}}$ & $97.1(1.4)^{\mathrm{b}}$ & $100.0(0.0)^{\mathrm{b}}$ \\
M. pigra & $90.1(1.6)^{\mathrm{c}}$ & $96.3(1.8)^{\mathrm{b}}$ & $97.7(2.3)^{\mathrm{b}}$ \\
A. nilotica & $39.2(3.0)^{\mathrm{a}}$ & $85.7(2.8)^{\mathrm{a}}$ & $90.3(2.9)^{\mathrm{a}}$ \\
P. pallida & $37.8(4.1)^{\mathrm{a}}$ & $76.3(4.4)^{\mathrm{a}}$ & $84.9(2.5)^{\mathrm{a}}$ \\
\hline
\end{tabular}

Although dormancy release in all four species was positively correlated with wet heat, only the two wetland species showed the strong quadratic relationship with wet heat that has previously been found to be an effective mechanism for P. aculeata (van Klinken and Flack, 2005). However, inter-species differences in responses were still apparent, with more $M$. pigra seeds being released from dormancy at lower temperatures $\left(20-25^{\circ} \mathrm{C}\right)$ and the temperature threshold for increased dormancy release being lower $\left(25-30^{\circ} \mathrm{C}\right.$ rather than $\left.30-35^{\circ} \mathrm{C}\right)$. Further testing would be required to determine whether these are species-level or population-level differences. Similar differences have been noted previously between different $P$. aculeata populations, possibly due to environmental differences during seed set (van Klinken and Flack, 2005). In contrast, the wet heat relationship in terrestrial species was relatively weak, with at least $12 \%$ of seeds still dormant after immersion for $14 \mathrm{~d}$ at $45^{\circ} \mathrm{C}$. Furthermore, no temperature response threshold was apparent for $P$. pallida, and was only apparent above $40^{\circ} \mathrm{C}$ for $A$. nilotica.

High, diurnally fluctuating temperatures have been shown to release seeds of some species from physical dormancy, thereby providing an effective gapdetection mechanism (Baskin and Baskin, 1998). A diurnal temperature fluctuation of $20^{\circ} \mathrm{C}\left(20 / 40^{\circ} \mathrm{C}\right.$; see also Lonsdale, 1993) was also identified as a dormancy-release mechanism for M. pigra (Dillon and Forcella, 1985). However, this was not supported by our study, which found that it was cumulative exposure to wet heat, not fluctuating temperatures per se, that was important. These contradictory results remain unexplained, but sensitivity cycling in response to field or or storage conditions is a possibility (van Assche et al., 2003; Jayasuriya et al., 2009). Furthermore, seeds can be naturally exposed to more extreme microclimates where fluctuating temperatures may become important. For example, soil surface temperatures above $60^{\circ} \mathrm{C}$ are not uncommon in northern Australia (McKeon and Mott, 1982; Lonsdale, 1993). Prolonged exposure to greater hot-dry temperature extremes ('dry heat' $>50^{\circ} \mathrm{C}$ ) is an important dormancy-release mechanism for some terrestrial species (McKeon and Mott, 1982; Baskin and Baskin, 1998; Ooi et al., 2012), but remains to be properly tested for our study species.

Wet heat responses have previously been demonstrated for submerged P. aculeata seeds (van Klinken and Flack, 2005), but our results demonstrate similar responses under saturated and humid $(80 \%$ relative humidity) conditions. This supports results from a detailed physiological study on Ipomoea lacunosa (Convolvulaceae) which demonstrated a wet heat response commencing between 79 and $88 \%$ relative humidity, although those seeds had already been made sensitive by storage on wet sand for 2 months, 
and were only exposed to up to $5 \mathrm{~h}$ of the treatment (Jayasuriya et al., 2009). Water availability did affect the time it took for dormancy-release in our study, resulting in up to a delay of several days for three of the four species (most notably at $45^{\circ} \mathrm{C}$ ). This has important implications under natural conditions. For example, weaker dormancy-release cues at lower moisture levels may still reduce the risk of seeds germinating when conditions for establishment are poor (van Klinken et al., 2008).

Our findings on habitat-specific dormancy-release mechanisms extend knowledge on dormancy-release mechanisms obtained in other studies, such as those focused on the role of fire as a dormancy-release trigger (Auld and O'Connell, 1991). A threshold response to wet heat has previously been demonstrated for $P$. aculeata to be an excellent strategy for maximizing the likelihood that germination will coincide with good recruitment conditions in diverse climates (arid to the wet-dry tropics) and habitats (wetlands, riparian and terrestrial) (van Klinken et al., 2008). It is therefore unsurprising to observe the same relationship for another wetland species, albeit from another subfamily. However, the same functional response to wet heat was not apparently important in the two terrestrial species we tested, at least below $45^{\circ} \mathrm{C}$, even though it can be an effective mechanism for optimizing germination timing in terrestrial habitats (van Klinken et al., 2008). One possible reason is that both our terrestrial species are dispersed through vertebrate herbivores (Mackey, 1995; van Klinken and White, 2011). Although consumption by animals is an important dormancy-release mechanism for both our study species (Haas et al., 1973; Mooney et al., 1977; Mackey, 1995; van Klinken and Campbell, 2009), the mechanism is probably through a combination of mechanical action and acidity (Baskin and Baskin, 1998). In contrast, a threshold response to wet heat in these species could in fact be maladaptive, resulting in dormancy release and possible imbibition of all seeds following exposure to hot $\left(38.6^{\circ} \mathrm{C}\right)$ wet conditions when passing through the digestive system. This would leave no means for optimally timing subsequent germination events, and seeds would germinate simultaneously, resulting in stronger sibcompetition. This study together with similar studies on dry heat (Auld and O'Connell, 1991; Ooi et al., 2012) open the way for comprehensive studies aimed at revealing the full suite of dormancy-release mechanisms for seeds with physical dormancy, and, most importantly, their ecological significance.

\section{Acknowledgements}

We thank Natasha Burrows (M. pigra) and Kunjithapatham Dhileepan (A. nilotica) for providing seeds,
Manon Griffith and Jo Vitelli for access to controlled temperature cabinets, Anne Bourne for data analyses, and Tony Grice and Chengyuan $\mathrm{Xu}$ for comments on a draft manuscript. Funding was provided by Ile de France Region through International Mobility Aid.

\section{References}

Allen, P.S. and Meyer, S.E. (1998) Ecological aspects of seed dormancy loss. Seed Science Research 8, 183-191.

Auld, T.D. and O'Connell, M. (1991) Predicting patterns of post-fire germination in 35 eastern Australian Fabaceae. Australian Journal of Ecology 16, 53-70.

Baskin, C.C., Baskin, J.M. and Li, X. (2000) Taxonomy, anatomy and evolution of physical dormancy in seeds. Plant Species Biology 15, 139-152.

Baskin, J.M. and Baskin, C.C. (1998) Seeds: Ecology, biogeography, and evolution of dormancy and germination. San Diego, Academic Press.

Baskin, J.M. and Baskin, C.C. (2004) A classification system for seed dormancy. Seed Science Research 14, 1-16.

Dillon, S.P. and Forcella, F. (1985) Fluctuating temperature breaks seed dormancy of catclaw Mimosa (Mimosa pigra). Weed Science 33, 196-198.

Gardner, G.K., Jacob, H.S., Steadman, K.J. and van Klinken, R.D. (2004) Effect of temperature, scarification and light on the dormancy and germination of three mesquite (Leguminoseae: Prosopis spp.) hybrids naturalized in Australia. pp. 566-570 in Sindel, B.M.; Johnson, S.B. (Eds) 14th Australian Weeds Conference papers and proceedings. Sydney, Weed Society of New South Wales.

Haas, Rh., Meyer, R.E., Scifres, C.J. and Brock, J.H. (1973) Growth and development of mesquite. Texas Agricultural Experiment Station Monograph 1, 10-19.

Hawkins, J.A., Boutaoui, N., Cheung, K.Y., van Klinken, R.D. and Hughes, C.E. (2007) Intercontinental dispersal prior to human translocations revealed in a cryptogenic invasive plant. New Phytologist 175, 575-587.

Hu, X.W., Wu, Y.P. and Wang, Y.R. (2009) Different requirements for physical dormancy release in two populations of Sophora alopecuroides in relation to burial depth. Ecological Research 24, 1051-1056.

Jayasuriya, K.M.G.G., Baskin, J.M., Geneve, R.L. and Baskin, C.C. (2009) A proposed mechanism for physical dormancy break in seeds of Ipomoea lacunosa (Convolvulaceae). Annals of Botany 103, 433-445.

Lonsdale, W.M. (1993) Losses from the seed bank of Mimosa pigra: soil micro-organisms vs. temperature fluctuations. Journal of Applied Ecology 30, 654-660.

Lonsdale, W.M. (1995) Mimosa pigra. pp. 169-188 in Groves, R.H.; Shepherd, R.C.H.; Richardson, R.G. (Eds) The biology of Australian weeds. Frankston, Victoria, R.G. and F.J. Richardson.

Lonsdale, W.M., Harley, K.L.S. and Gillett, J.D. (1988) Seed bank dynamics in Mimosa pigra an invasive tropical shrub. Journal of Applied Ecology 25, 963-976.

Mackey, A.P. (1995) Acacia nilotica. pp. 7-17 in Groves, R.H.; Shepherd, R.C.H.; Richardson, R.G. (Eds) The biology of Australian weeds. Frankston, Victoria, R.G. and F.J. Richardson.

Mareno-Casasola, P., Grime, J.P. and Martinez, M.L. (1994) A comparative study of the effects of fluctuations in 
temperature and moisture supply on hard coat dormancy in seeds of coastal tropical legumes in Mexico. Journal of Tropical Ecology 10, 67-86.

McDonald, C.K. (2002) Germination responses to temperature in tropical and subtropical pasture legumes. 1. Constant temperatures. Australian Journal of Experimental Agriculture 42, 407-419.

McKeon, G.M. and Mott, J.J. (1982) The effect of temperature on the field softening of hard seed of Stylonanthes humilis and S. hamata in a dry monsoonal climate. Australian Journal of Experimental Agriculture 33, 75-85.

Mooney, H.A., Simpson, B.B. and Solbring, O.T. (1977) Phenology, morphology, physiology. pp. 26-43 in Simpson, B.B. (Ed.) Mesquite-its biology in two desert scrub ecosystems. Stroudsburg, Pennsylvania, Dowden, Hutchinson, and Ross.

Morrison, D.A., McClay, K., Porter, C. and Rish, S. (1998) The role of the lens in controlling heat-induced breakdown of testa-imposed dormancy in native Australian legumes. Annals of Botany 82, 35-40.

Norman, H.C., Cocks, P.S. and Galwey, N.W. (2002) Hardseededness in annual clovers: variation between populations from wet and dry environments. Australian Journal of Agricultural Research 53, 821-829.

Ooi, M.K.J., Auld, T.D. and Denham, A.J. (2012) Projected soil temperature increase and seed dormancy response along an altitudinal gradient: implications for seed bank persistence under climate change. Plant and Soil 353, 289-303.

Smith, C., van Klinken, R.D., Seabrook, L. and McAlpine, C. (2012) Estimating the influence of land management change on weed invasion potential using expert knowledge. Diversity and Distributions 18, 818-831.

Tewari, J.C., Pasiecznik, N.M., Harsh, L.N. and Garris, P.J.C. (1998) Prosopis, commonly called mesquite, is distributed in the arid and semi-arid parts of the tropical and sub- tropical regions. The Prosopis Society of India and The Henry Doubleday Research Association, Jodhpur, 128.

Thompson, K. and Ooi, M.K.J. (2013) Germination and dormancy breaking: two different things. Seed Science Research 23, 1.

Thorpe, J.R. and Lynch, R. (2000) The determination of weeds of national significance. Launceston, Australia, National Weeds Strategy Executive Committee.

van Assche, J.A., Debucquoy, K.L.A. and Rommens, W.A.F. (2003) Seasonal cycles in the germination capacity of buried seeds of some Leguminosae (Fabaceae). New Phytologist 158, 315-323.

van Klinken, R.D. and Campbell, S. (2009) Prosopis spp. pp. 238-273 in Panetta, F.D. (Ed.) The biology of Australian weeds. Vol. 3. Frankston, Victoria, R.G. and F.J. Richardson.

van Klinken, R.D. and Flack, L. (2005) Wet heat as a mechanism for dormancy release and germination of seeds with physical dormancy. Weed Science 53, 663-669.

van Klinken, R.D. and White, A.J. (2011) Overcoming seasonally fluctuating resources: bruchid predation of mesquite (Prosopis) seed in dung. Biological Control 59, 361-365.

van Klinken, R.D., Flack, L. and Pettit, W. (2006) Wet-season dormancy release in seed banks of a tropical leguminous shrub is determined by wet heat. Annals of Botany 98, 875-883.

van Klinken, R.D., Lukitsch, B. and Cook, C. (2008) Interaction between seed dormancy-release mechanism, environment and seed bank strategy for a widely distributed perennial legume, Parkinsonia aculeata (Caesalpinaceae). Annals of Botany 102, 255-264.

van Klinken, R.D., Campbell, S.D., Heard, T.A., McKenzie, J. and March, N. (2009) The biology of Australian weeds, Parkinsonia aculeata L. Plant Protection Quarterly 24, 100-117. 